\title{
Prevalence of mosquitoes (diptera: culicidae) in and around Bangladesh Agricultural University campus of Mymensingh in Bangladesh
}

\author{
N Alam ${ }^{1}$, T Farjana ${ }^{*}$, TF Khanom², SS Labony ${ }^{1}$, KR Islam $^{1}$, \\ S Ahmmed ${ }^{1}$, MMH Mondal ${ }^{1}$ \\ ${ }^{1}$ Department of Parasitology, ${ }^{2}$ Department of Environmental Science, Bangladesh Agricultural University, \\ Mymensingh 2202, Bangladesh
}

\begin{abstract}
Mosquitoes are the small insects belonging to the order diptera. They are familiar parasitic vectors of a number of transmissible and life menacing diseases. The study was conducted at the Bangladesh Agricultural University (BAU) campus and its surrounding areas in Mymensingh, Bangladesh from January to June, 2013 detect adult mosquito species and their status. Adult mosquitoes were collected using light traps (LTs), insect collecting nets, and human bait (HB) from households, cattle sheds, rice field, botanical garden, dairy farm and poultry farm and staff residential quarters. A total of 2,750 adult mosquitoes were collected from these places. Ten species of mosquitoes under two genera were identified. Among the two genera Culex (84.3\%) was the leading group dominated over Anopheles (15.7\%) in all areas. In case of Culex species, the most prevalent mosquito species was the $C x$. quinquefasciatus (39\%) followed by $C x$. fuscocephala (23.7\%), Cx. tritaeniorhynchus (15.8\%), Cx. gelidus (4.0\%), Cx. whitmorei (1.2\%), Cx. vishnui (0.3\%) and $C x$. whitei (0.3\%). On the other hand, among Anopheles species, An. bengalensis (11.1\%) was found in the highest percentage followed by An. vagus (3.8\%) and An. jayporiensis (0.8\%). Among the studied areas, the highest prevalence of mosquitoes were collected from cattle sheds (40.7\%), followed by households of Balashpur (16.2\%), Boyra (14.9\%) and Kewatkhali (12.4\%). Though Culex species was found as dominant species in all areas, the highest percentage (96.7\%) was found in staff residential area in BAU campus, whereas, the highest prevalence of Anopheles species (28.7\%) was found in cattle shed. We found that two genera were prevalent together in almost all areas, however, though Culex was the dominant one. In conclusion, our survey provided useful information on the prevalence of mosquito species regarding the distribution and diseases control.
\end{abstract}

Key words: Mosquito, prevalence, Anopheles, Culex, Mymensingh, Bangladesh

Progressive Agriculturists. All rights reserve

*Corresponding Author: : thahsinfarjana@gmail.com

\section{Introduction}

Now a day's mosquitoes are regarded as a wellknown vector of many deadly diseases like dengue, Japanese encephalitis, yellow fever, malaria, and filariasis (Halstead, 1966; Bang, 1985). They are also important nuisance pests. Mosquito borne diseases are the major public health problem in Bangladesh (Aziz et al., 1967; Wolfe and Aslamkhan, 1971, Rosenberg and Maheswary, 1982, Ahmed et al., 1986, Khan and Ahmed, 1986 and Hossain et al., 2000). In fact, mosquitoes and mosquito borne diseases are big challenge for human from the beginning of the history of mankind. This battle has resulted into research works to enable man to know about mosquitoes, so they can be controlled. Mosquitoes are widely distributed throughout the world; however, they are predominantly tropical insects. Currently more than 3000 mosquito species are prevalent in the world belonging in 39 genera and 135 subgenera, of which about 100 are vectors of human diseases (Clements, 1992; Reinert, 2000; 
Reinert, 2001). Important genera are Anopheles, Culex, Aedes, Mansonia, Psorophora, and Haemagogus. The female mosquito has needle-like piercing- sucking type mouthparts and sucks blood from different vertebrate hosts. A blood meal is essential before laying eggs. Of $>3000$ species, only 113 species have been recorded in Bangladesh (Ahmed, 1987).

Of the Anopheles species, only four namely $A n$. dirus, An. philippinensis, An. minimus, and An. sundaicus has been established as malaria vectors in Bangladesh (Ahmed 1987). However, the Ministry of Health claims malarial parasite positivity in four additional species An. aconitus, An. vagus, An. annularis, and An. maculatus var willmorei (Ahmed 1987). Bangladesh often experiences two malaria peaks in a year one in pre-monsoon (May-June) time, another in post-monsoon (Octover-November) time. Among the non-malarial diseases, filariasis is transmitted by Culex quinquefasciatus and Mansonia speices; dengue, a viral disease, is suspected to spread by Aedes aegypti and Ae. albopictus and a still less known Japanese encephalitis disease is transmitted by $C x$. tritaeniorhynchus (Khan et al. 1981).

Mosquito-borne diseases, other than malaria, are becoming important public health problems in Bangladesh. Aslamkhan and Wolfe (1972) gave evidence that filariasis had been present since many years in former East Pakistan, now Bangladesh. Their surveys indicated that bancroftian filariasis is present in all districts with the highest prevalence (14\%) in Dinajpur district, especially in the northwest part of the district. Other important foci are in Chittagong Hill Tracts, Rangpur, Pabna, and Barisal districts and Dhaka. Wolfe and Aslamkhan (1971) reported Culex pipiens fatigans as the primary vector of rural bancroftian filariasis in Thakurgaon thana. In fact this mosquito is present in large numbers throughout Bangladesh and it is likely to be the main vector of filariasis all over the country. Wolfe and Aslamkhan (1971) noted that numerous ponds or tanks of water with ideal breeding conditions for Mansonia spp., the usual vectors of Brugia malayi, are common and that suitable conditions for the propagation of this species exist in many parts of
Bangladesh. They referred to a report of B. malayi infection in human from monkeys in the northern Chittagong Hill Tracts, indicating the possibility of an animal reservoir for human infection in this area. Mosquito larvae breed in different types of wet containers. Larval breeding habitats include a wide variety of ground water accumulations as well as tree-holes, bamboo stumps, internodes, leaf axils, pitcher plants and varieties of container (any types of water reservoir), both indoor and outdoor. Bangladesh Agricultural University campus and surrounding areas have diverse ecological habitats and vegetation essential for mosquito breeding. The niches available in campus consist of rice fields and cultivated lands, human settlements (e.g. houses, academic and administrative buildings and residential halls), various wetlands (e.g. road side lakes, drains, ponds etc). All these habitats provide suitable breeding place for mosquitoes. It has been identified that the radical approach to combat mosquitoes today is equally linked to the effective ways of controlling mosquito-borne diseases. Therefore, emphasis should be given on the effective and integrated vector control studies through detail knowledge of prevalence and species distribution of mosquito vectors in certain localities. This study was therefore designed to investigate the prevalence and species distribution of mosquitoes at BAU campus and its surrounding areas in Mymensingh.

\section{Materials and Methods}

\section{Study areas and study period}

The study of the population dynamics of mosquito species were carried out in nine localities (Kawatkhali, Boyra, Balashpur, poultry farm, dairy farm, staff residential area, garden, rice field, and cow sheds) at Bangladesh Agricultural University (BAU) campus and its surrounding areas, namely Kewatkhali, Boyra, and Balashpur in Mymensingh. The study was carried out from January to June, 2013.

\section{Procedures of mosquito collection}

Adult mosquitoes were collected in different periods of the day and from different types of niches such as, cattle-biting mosquitoes from cow sheds using 
mosquito collecting net resting or biting on any part of a cattle. In the household area, mosquitoes were collected from bed rooms, bath-room and also from drawing rooms in day times using the mosquito net. Mosquitoes were collected from behind and beside the cupboards, inside old shoes and wooden crates, underneath shelves, and on hanging clothes, etc. in the evening using light traps (LTs). Mosquitoes were also collected from dairy farm and poultry farm of BAU campus at day time. Moreover, we collected mosquitoes from drains, store houses, ponds present in and around the dairy and poultry farm. All mosquitoes that bite or lodged on a man in bed rooms during the day time, i.e. from dawn to dusk, were collected by human bait (HB) method. In addition, mosquitoes were collected from garden and rice fields.

\section{Identification of mosquitoes}

Mosquitoes were identified under microscope preparing simple or permanent slides following the morphological descriptions, diagnostic characteristics and keys given by Barraud (1934) and Bram (1967).

\section{Statistical analysis}

Student's "t" test was done to compare the number of Culex and Anopheles mosquitoes in different study areas. To find out the differences between male and female mosquitoes Chi-square goodness of fit test was done and $\mathrm{P} \leq 0.05$ was considered as statistically significant.

\section{Results and Discussion}

\section{We identified 10 species of mosquitoes belonging to two important genera}

A total of 2,750 adult mosquitoes were collected from different places of BAU campus and surrounding areas during the study period (January to June, 2013). The collected mosquitoes were under the family Culicidae. Altogether ten species of mosquitoes under two genera were identified. The identified two genera were Culex (Cx.) and Anopheles (An). The identified species were $A n$. bengalensis, An. vagus, An. jeyporiensis, CX. fuscocephala, $C x$. quinquefasciatus, $C x$. tritaeniorhynchus, Cx. gelidus, Cx. vishnui, Cx. whitmorei, Cx. whitei (Figure 1). Aedes mosquito was not found during this study. Among the two
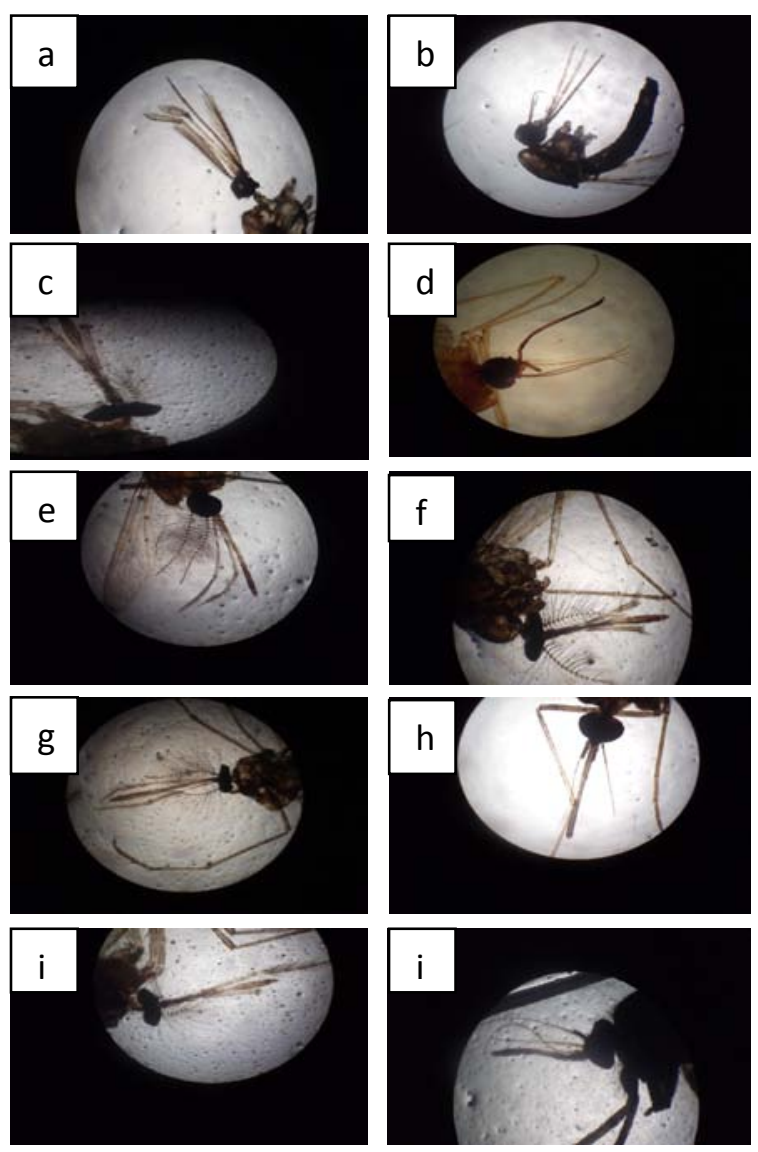

Figure 1. Adult mosquitoes were collected from BAU campus and surrounding areas using mosquito collecting nets and identified under microscope (40x 100 objective). An. bengalensis (a), An. vagus (b), An. jeyporiensis (c), Cx. fuscocephala (d), Cx. quinquefasciatus (e), Cx. tritaeniorhynchus (f), Cx. gelidus (g), Cx. vishnui (h), Cx. whitmorei (i), Cx. whitei (j).

genera Culex (84.3\%) was the leading group dominated over Anopheles (15.7\%) in all studied areas. In case of Culex species, the most prevalent mosquito species was the $C x$. quinquefasciatus (39\%) followed by $C x$. fuscocephala (23.7\%), $C x$. tritaeniorhynchus (15.8\%), Cx. gelidus (4.0\%), Cx. whitmorei (1.2\%), $C x$. vishnui (0.3\%) and $C x$. whitei (0.3\%). On the other hand, among Anopheles species, 
An. bengalensis (11.1\%) was found the most common followed by An. vagus (3.8\%) and An. jayporiensis $(0.8 \%)$ (Table 1$)$. The similar findings were reported by Aslamkhan and Wolf (1971) in Dhaka city and Ameen and Moizuddin (1973) in Dinajpur district. The occurrence of Culex species recorded in this study conforms to the findings of Anosike et al. (2007) and Hopkins (1952).

Table 1. Mosquito species collected from BAU campus and it's surrounding areas

\begin{tabular}{|l|l|c|c|}
\hline Genus & Species & $\begin{array}{c}\text { No. of } \\
\text { mosquito }\end{array}$ & $\begin{array}{c}\text { Abundance } \\
(\mathbf{\%})\end{array}$ \\
\hline Culex & CX. quinquefasciatus & 1072 & 39.0 \\
\cline { 2 - 4 } & CX. fuscocephala & 651 & 23.7 \\
\cline { 2 - 4 } & CX. tritaeniorhynchus & 435 & 15.8 \\
\cline { 2 - 4 } & Cx. gelidus & 111 & 4.0 \\
\cline { 2 - 4 } & Cx. whitmorei & 34 & 1.2 \\
\cline { 2 - 4 } & CX. vishnui & 8 & 0.3 \\
\cline { 2 - 4 } & CX. whitei & 7 & 0.3 \\
\cline { 2 - 4 } & Subtotal & $\mathbf{2 3 1 8}$ & $\mathbf{8 4 . 3}$ \\
\hline Anopheles & An. bengalensis & 305 & 11.1 \\
\cline { 2 - 4 } & An. vagus & 105 & 3.8 \\
\cline { 2 - 4 } & An. jeyporiensis & 22 & 0.8 \\
\cline { 2 - 4 } & Subtotal & $\mathbf{4 3 2}$ & 15.7 \\
\hline & Total & $\mathbf{2 7 5 0}$ & -- \\
\hline
\end{tabular}

Culex species usually breed profusely in polluted gutters, blocked drains and other water retention habitats with organic matter but Aedes and Anopheles mosquitoes which prefer clean ground pools and man-made containers, respectively (Khan and Ahmed, 1986). The study area had many polluted drains and runoffs providing conducive environment for the prolific breeding of Culex species. Culex species has been noted to be very common in polluted waters and sites which have foul smell (Anosike et al., 2007), and the mosquitoes collected in this study were done mostly from dirty places of houses, polluted drains, ditches, cowsheds, poultry farm having foul smell, and waste products. Culex quinquefasciatus is widely distributed in urban and rural areas of Bangladesh due to the presence of many irrigation ditches and rice fields provides suitable breeding site for this mosquito (Hossain et al., 1996).

\section{Mosquitoes were most abundant in the cattle sheds}

Among the studied areas, the highest prevalence of mosquitoes were detected in cattle sheds (40.7\%), followed by households of Balashpur (16.2\%), Boyra (14.9\%) and Kewatkhali (12.4\%). A total of 1120 adult mosquitoes were collected from cattle sheds of Boyra, Balashpur, and Kewatkhali of which 798 (71.3\%) were Culex and 322 (28.7\%) were Anopheles. On the other hand, though Culex species was found dominant species in all areas but it was most abundant $(96.7 \%)$ in staff residential area in BAU campus. However, the highest prevalence of Anopheles species (28.7\%) was found in cattle sheds. Importantly, prevalence of mosquitoes was the lowest in botanical garden (1.1\%), poultry farm (1.3\%) and dairy farm (1.8\%) (Table 2). The presence of high percentage of mosquitoes in cowshed may be due to the presence of cow dung, surrounding polluted water and the darkness of the cowshed.

Among the 9 species collected from cattle sheds, $C x$. qunquefasciatus (16.8\%) was the most prevalent followed by $C x$. fuscocephala (9.3\%) and $A n$. bengalensis (8.6\%) (Table 3). Cx. quinquefasciatus grows relatively darker places (Senior-White, 1926), and cowsheds were usually dark in the study areas. Possibly faulty construction, stagnant drain water, ponds, lakes and also geographic location play critical role in the wide distribution of $C x$. quinquefasciatus over the localities which conforms to the findings reported in Dhaka city (Ahmed, 1996).

A total of 446 adult mosquitoes were collected from household of Balashpur in which Culex were 390 (96.4\%) and Anopheles were 16 (3.4\%). In Balashpur, Cx. tritaeniorhynchus (6.9\%) was little bit more prevalent than $C x$. quinquefasciatus (4.9\%) (Table 3). Of 342 adult mosquitoes collected from houses of Kewatkhali, Culex were 312 (91.2\%) and Anopheles were 30 (8.8\%) (Table 2). Interestingly, the prevalence of $C x$. quinquefasciatus (8.1\%) was the highest in Kewatkhali (Table- 3). Among 412 adult mosquitoes collected from household of Boyra, Culex were 372 (90.3\%) and Anopheles were 40 (3.7\%) (Table 2); and $C x$. fuscocephala was more prevalent species in Boyra (3.3\%) (Table 3). A total of 240 adult mosquitoes were collected from BAU staff residential area in which Culex were 232 (96.7\%) and Anopheles were 8 (3.3\%) (Table-2), 
where most prevalent species was $C x$. Fuscocephala (3.3\%) (Table 3). Our results provide evidences that $C x$. quinquefasciatus, $C x$. tritaeniorhynchus, and $C x$. fuscocephala were the most common species in BAU Campus, Boyra, Kewatkhali and Balashpur. Though $C x$. quinquefasciatus and $C x$. tritaeniorhynchus have

Table 2. Prevalence of male and female Culex and Anopheles mosquitoes collected from different study areas.

\begin{tabular}{|c|c|c|c|c|c|c|c|}
\hline \multirow[b]{2}{*}{ No. } & \multirow[b]{2}{*}{ Place } & \multicolumn{5}{|c|}{ No. of mosquitoes } & \multirow[b]{2}{*}{ P-value } \\
\hline & & Total (\%) & Culex (\%) & Anopheles (\%) & Female (\%) & Male (\%) & \\
\hline 1 & Cattle sheds & $1120(40.7)$ & $798(71.3)$ & $322(28.7)$ & 964a(86.07) & $156^{\mathrm{b}}(13.9)$ & $0.001^{\star *}$ \\
\hline 2 & Balashpur & $446(16.2)$ & $430(96.4)$ & $16(3.6)$ & $324^{a}(72.6)$ & $122^{b}(27.3)$ & $0.035^{*}$ \\
\hline 3 & Kawatkhali & $342(12.4)$ & $312(91.2)$ & $30(8.8)$ & $210^{a}(61.4)$ & $132^{b}(38.5)$ & $0.004^{\star}$ \\
\hline 4 & Boyra & 412(14.9) & $372(90.3)$ & $40(9.7)$ & $304 a(73.6)$ & $108^{b}(26.3)$ & $0.042^{\star}$ \\
\hline 5 & Staff residential area & $240(8.7)$ & $232(96.7)$ & $8(3.3)$ & $214^{a}(89.1)$ & $26^{\mathrm{b}}(10.8)$ & $0.001^{* \star}$ \\
\hline 6 & Dairy farm & $50(1.8)$ & $44(88)$ & $6(12)$ & $30^{\mathrm{a}}(60)$ & $20^{\mathrm{b}}(40)$ & $0.005^{*}$ \\
\hline 7 & Poultry farm & $36(1.3)$ & $33(91.7)$ & $3(8.3)$ & $29^{\mathrm{a}}(80.5)$ & $7^{b}(19.5)$ & $0.001^{* *}$ \\
\hline 8 & Botanical garden & $30(1.1)$ & $27(90)$ & $3(10)$ & $17^{a}(56.6)$ & $13^{\mathrm{b}}(43.4)$ & $0.002^{\star}$ \\
\hline 9 & Agronomy rice field & $74(2.6)$ & $70(94.6)$ & $4(5.4)$ & $43^{\mathrm{a}}(56.5)$ & $31^{\mathrm{b}}(43.4)$ & $0.001^{* *}$ \\
\hline & & 2750 & 2318 & 432 & $2135^{\mathrm{a}}(77.6)$ & $615^{b}(22.4)$ & $0.001^{\star \star}$ \\
\hline
\end{tabular}

Values with different superscripts within a row differ significantly, ${ }^{*} P<0.05,{ }^{* *} \mathrm{P}<0.01$

Table 3. Prevalence of different species of Culex and Anopheles in different study areas

\begin{tabular}{|c|c|c|c|c|c|c|c|c|c|c|}
\hline \multicolumn{2}{|l|}{ Species } & \multirow{2}{*}{$\begin{array}{c}\begin{array}{c}\text { Cattle } \\
\text { sheds }\end{array} \\
463 \\
\end{array}$} & \multirow{2}{*}{$\begin{array}{c}\text { Balashpur } \\
135\end{array}$} & \multirow{2}{*}{$\begin{array}{c}\text { Kewatkhali } \\
223\end{array}$} & \multirow{2}{*}{$\begin{array}{c}\text { Boyra } \\
147\end{array}$} & \multirow{2}{*}{$\begin{array}{c}\begin{array}{c}\text { Staff } \\
\text { residential } \\
\text { area }\end{array} \\
55\end{array}$} & \multirow{2}{*}{ 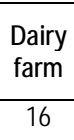 } & \multirow{2}{*}{$\begin{array}{c}\begin{array}{c}\text { Poultry } \\
\text { farm }\end{array} \\
3\end{array}$} & \multirow{2}{*}{$\begin{array}{c}\text { Garden } \\
3\end{array}$} & \multirow{2}{*}{$\begin{array}{c}\text { Agronomy } \\
\text { rice field }\end{array}$} \\
\hline & No. & & & & & & & & & \\
\hline quinquefasciatus & $\%$ & 16.8 & 4.9 & 8.1 & 5.3 & 2 & 0.6 & 0.1 & 0.1 & 1 \\
\hline \multirow{2}{*}{$\begin{array}{c}C X . \\
\text { tritaeniorhynchus }\end{array}$} & No. & 28 & 189 & 7 & 113 & 71 & 0 & 13 & 9 & 5 \\
\hline & $\%$ & 1 & 6.9 & 0.3 & 4.1 & 2.6 & 0 & 0.5 & 0.3 & 0.2 \\
\hline \multirow{2}{*}{ Cx. fuscocephala } & No. & 256 & 85 & 73 & 96 & 90 & 11 & 15 & 13 & 12 \\
\hline & $\%$ & 9.3 & 3.1 & 2.7 & 3.5 & 3.3 & 0.4 & 0.5 & 0.5 & 0.4 \\
\hline \multirow{2}{*}{ CX. gelidus } & No. & 40 & 14 & 9 & 8 & 16 & 0 & 0 & 1 & 23 \\
\hline & $\%$ & 1.5 & 0.5 & 0.3 & 0.3 & 0.6 & 0 & 0 & 0.04 & 0.8 \\
\hline \multirow{2}{*}{ CX. vishnui } & No. & 0 & 0 & 0 & 8 & 0 & 0 & 0 & 0 & 0 \\
\hline & $\%$ & 0 & 0 & 0 & 0.3 & 0 & 0 & 0 & 0 & 0 \\
\hline \multirow{2}{*}{ CX. whitmorei } & No. & 11 & 7 & 0 & 0 & 0 & 10 & 2 & 1 & 3 \\
\hline & $\%$ & 0.4 & 0.3 & 0 & 0 & 0 & 0.4 & 0.1 & 0.04 & 0.1 \\
\hline \multirow{2}{*}{ Cx. whitei } & No. & 0 & 0 & 0 & 0 & 0 & 7 & 0 & 0 & 0 \\
\hline & $\%$ & 0 & 0 & 0 & 0 & 0 & 0.3 & 0 & 0 & 0 \\
\hline \multirow{2}{*}{ An. bengalensis } & No. & 239 & 8 & 18 & 24 & 6 & 3 & 3 & 0 & 4 \\
\hline & $\%$ & 8.6 & 0.3 & 0.7 & 0.8 & 0.2 & 0.1 & 0.1 & 0 & 0.2 \\
\hline \multirow{2}{*}{ An. vagus } & No. & 63 & 6 & 12 & 16 & 2 & 3 & 0 & 3 & 0 \\
\hline & $\%$ & 2.3 & 0.2 & 0.4 & 0.6 & 0.1 & 0.1 & 0 & 0.1 & 0 \\
\hline \multirow{2}{*}{ An. jeyporiensis } & No. & 20 & 2 & 0 & 0 & 0 & 0 & 0 & 0 & 0 \\
\hline & $\%$ & 0.7 & 0.1 & 0 & 0 & 0 & 0 & 0 & 0 & 0 \\
\hline
\end{tabular}

the similar spatial distribution, all these species can breed in the similar habitats (Ameen and Moizuddin, 1973; Ahmed, 1996) but the former species grows relatively darker places (Senior-White, 1926). The species An. vagus (3.8\%), Cx. whitei (0.3\%), Cx. vishnui (0.3\%), Cx. whitmorei $(0.8 \%)$ were in negligible number in this study conforming the findings showed by Jannat et al. (2005) in Jahangirnagar University area. Among Anopheles species, An. bengalensis was dominant species (11.1\%), whereas prevalence of An. vagus (3.8\%) 
and An. jayporiensis (0.8\%) were very low. the similar spatial distribution, all these species can breed in the similar habitats (Ameen and Moizuddin, 1973; Ahmed, 1996) but the former species grows relatively darker places (Senior-White, 1926). The species An. vagus (3.8\%), CX. whitei (0.3\%), CX. vishnui $(0.3 \%), C x$. whitmorei $(0.8 \%)$ were in negligible number in this study conforming the findings showed by Jannat et al. (2005) in Jahangirnagar University area. Among Anopheles species, An. bengalensis was dominant species (11.1\%), whereas prevalence of An. vagus (3.8\%) and An. jayporiensis (0.8\%) were very low. The similar abundance of these species also observed in different studies by Castro et al. (2010) in Dar Es Salaasm, Tanzania and Bashar et al. (2005) in rural areas around Jahangirnagar University, Bangladesh.

\section{Female mosquitoes were more abundant}

Prevalence of female mosquitoes (77.6\%) were significantly higher $(\mathrm{P}<0.01)$ than that of males (22.4\%) in human houses, and animal and poultry sheds located in all studied regions. The highest percentage of female mosquitoes were found (89.1\%) in staff residential area and the lowest (56.5\%) in rice fields (Table-2). Female mosquitoes suck blood which is essential for their breeding (Clements, 1992). Female mosquitoes usually enter into the houses for blood feeding. On the contrary, in agronomy fields, males and females were almost equal in percentage ( $43.5 \%$ and $56.5 \%$, respectively), which might be due to the absence of animal or human hosts.

\section{Conclusions}

This survey provides useful information on the prevalence and distribution of mosquito species. Taken together, our results indicate that all the places studied are very much vulnerable to mosquito-borne diseases. Although the survey was limited at BAU campus and its surrounding areas, but basic information obtained is also applicable to other region in Bangladesh.

\section{References}

Ahmed TU (1987). Checklist of the mosquito of Bangladesh. Mosquito Systematic. 19:187-200

Ahmed TU (1996). Mosquito problem in Bangladesh with special emphasis on urban mosquito situation and its control. Key note presentation at the conference of the Entomological Society of Bangladesh in Dhaka city, Bangladesh, pp: 10- 25.

Ahmed TU, Maheswary NP, Khan NI (1986). Filariasis in Mirpur area of Dhaka City, Bangladesh. Medical Research Council Bulletin 12: 83-94.

Ameen M, Hossain MI, Chowdhury MA (1999). Integrated mosquito management in Dhaka city: Promising non-chemical components. Proceedings of the $3^{\text {rd }}$ International Conference on Urban Pests held in Prague, Czech Republic, pp. 678.

Ameen M, Moizuddin M (1973). Bionomics of the common mosquitoes of Dacca. Journal of Natural History 7: 1 - 21.

Anosike JCBE, Nwoke AN, Okere EE, Oku JE, Asor IO, Emmy-Egb, Adimike DA (2007). Epidemiology of tree-hole breeding mosquitoes in the tropical rainforest of Imo state, South East Nigeria. Annals of Agricultural Environment and Medicine14: 31-38.

Aslamkhan M, Wolfe MS (1972). Bancroftian filariasis in two villages in Dinajpur District, East Pakistan. The American Society for Tropical Medicine and Hygiene 21: 30-37.

Aziz MA, Gorham JR, Greg MB (1967). "Dacca fever", an outbreak of Dengue. Pakistan Journal of Medical Research 6: 83-92.

Bang YH (1985). Integrated management of urban mosquito vectors of diseases. Journal of Communicable Disease 17: 1-10.

Barraud PJ (1933). The fauna of British India, including Ceylon and Burma, Diptera, Family-Culicidae, Tribes-Megarhinini and Culicini. Taylor and Francis, London, 463.

Bashar K, Samsuzzaman M, Ullah MS, Iqbal MJH (2005). Surveillance of Dengue vectors 


\section{Prevalence of mosquitoes in BAU campus}

mosquito in some rural areas of Bangladesh. Pakistan Journal of Biological Sciences 8: 1119-1122.

Bram RM (1967). Contribution to the mosquito fauna to South-East Asia, II. The genus Culex in Thailand (Diptera; Culicidae). Contribution to American Entomological Institute 2: 1-296.

Castro MC, Kanamori S, Kannady K., Mkude S, Killeen GF, Fillinger U, (2010). The importance of drains for the larval development of lymphatic filariasis and malaria vectors Dar Es Salaam, United Republic of Tanzania. PLoS One 4: 693699.

Clements AN (1992). The Biology of Mosquitoes, Vol.1. Development, Nutrition and Reproduction. Chapman \& Hall, New York, pp: 26-45.

Fillinger U, Sonye G, Killeen GF, Knols BG, Becker $N$ (2004). The practical importance of permanent and semi-permanent habitats for controlling aquatic stages of Anopheles gambae sensu latu mosquitoes; operational observation from a rural town in western Kenya. Tropical Medicine and International Health 9: 1274-1289.

Gubler DJ (2002). Epidemic dengue/ dengue hemorrhagic fever as a public health, social and economic problem in 21st century. Trands Microbiology 10: 100103.

Halstead SB (1966). Mosquito-borne haemorrhagic fevers of South and South-East Asia. Bulletin of World Health Organization 35: 3-15.

Hopkins GHE (1952). Mosquitoes of Ethiopian region, I. Larval Bionomics of Mosquitoes and Taxonomy of Culicine Larvae. $1^{\text {st }}$ Edition, British Museum (Natural History), London, 335.

Hossain MI, Wagatsuma Y, Chowdhury MA, Ahmed TU, Uddin MA, Sohel SMN Kittayapong $P$ (2000). Analysis of some socio demographic factors related to DF/DHF outbreak in Dhaka city. Dengue Bulletin 24: 34-41.
Hossain MI, Ameen M, Chowdhury MA (1996). Mosquito breeding grounds in the city of Dhaka. Journal of Life Science 8: 41-47.

Jannat KNE, Baqui MA, Ahmed TU (2005). The status of dengue vector mosquito Aedes spp. in Dhaka. Bangladesh Journal of Life Science 17: 15-23.

Khan M, Ahmed TU (1986). Dengue status in Bangladesh. Dengue News Letter. 12:11.

Khan AM, Khan AQ, Dobrzynasky L., Joshi GP Hung M (1981) A Japanese encephalitis focus in Bangladesh. American Journal of Tropical Medicine and Hygiene 48: 41-44.

Reinert JF (2000). New classification for the composite genus Aedes (Diptera:Culicidae:Aedinii), elevation of subgenus Ochlerotatus to generic rank, reclassification of the other subgenera and notes on certain subspecies. Journal of American Mosquito Control Association 16: 175-188.

Reinert JF (2001). Revised list of abbreviations for genera and subgenera of Culicidae (Diptera) and notes on generic and subgeneric changes. Journal of American Mosquito Control Association 17: 51-55.

Rosenberg R, Maheswary NP (1982). Forest Malaria in Bangaldesh. American Journal of Tropical Medicine and Hygiene 31: 175182.

Saleeza SNR, Norma-Rashid Y, Azirun S, (2011). Mosquito larval breeding habitat in urban and sub-urban areas, Peninsular Malaysia. World Academy of Science, Engineering and Technology 58: 569.

Senior-White R (1926). Physical factors in mosquito ecology. Bulletin of Entomological Research 16: 187-248.

Service MW (1993). Mosquitoes (Culicidea) In Medical insects and Arachnids._(R.P. Lane \& R.W. Grosskey, eds.) Chapman and Hall, London, pp. 238.

Wolfe MS, Aslamkhan M (1971). Filariasis in East Pakistan. Transaction of Royal Society Tropical Medicine and Hygiene 65: 6369. 

Alam et al. (2015), Progressive Agriculture 26: 60-66 